\title{
Increasing of Syncytial Knot and Fibrinoid Deposit in High-Cd Accumulated Human Placentas
}

\author{
Aumento del Nodo Sincicial y Depósitos de Fibrinoide en \\ Placenta Humanas con Alta Acumulación de Cadmio
}

\begin{abstract}
Laorrat Phuapittayalert; Thongchai Norkaew**; Wisa Supanpaiboon ${ }^{* * * *}$; Supaporn Chuenchoojit ${ }^{* * * *}$; Wiphawi Hipkeao ${ }^{* * * * *}$; Witaya Swaddiwudhipong ${ }^{* * * * * *}$ \& Natthiya Sakulsak ${ }^{*}$
\end{abstract}

PHUAPITTAYALERT, L.; NORKAEW, T.; SUPANPAIBOON, W.; CHUENCHOOJIT, S.; HIPKEAO, W.; SWADDIWUDHIPONG, W. \& SAKULSAK, N. Increasing of syncytial knot and fibrinoid deposit in high-Cd accumulated human placentas. Int. J. Morphol., 31(4):1210-1215, 2013.

SUMMARY: A toxic metal, cadmium (Cd), can accumulate in human organs. Placenta is usually used as indicator organ for Cd exposure. Therefore, we aim to investigate the different of placental morphology between the low- and high-Cd accumulated placentas. The samples were collected from 14 pregnant women who resided in low-Cd contaminated (L-Cd group) and high-Cd contaminated (H$\mathrm{Cd}$ group) areas. The concentrations of $\mathrm{Cd}$ in blood (B-Cd), urine (U-Cd) and placentas (P-Cd) were measured by ICP-MS and AAS. The morphological appearance of placentas was examined by using routine paraffin section and $\mathrm{H} \& \mathrm{E}$ staining. The results showed that levels of B-Cd, U-Cd and P-Cd were significantly higher in $\mathrm{H}-\mathrm{Cd}$ group than in L-Cd group ( $\mathrm{p}=0.001)$. Moreover, the B-Cd was positively correlated with $\mathrm{U}-\mathrm{Cd}(\mathrm{rs}=0.823, \mathrm{p}=0.000)$ and $\mathrm{P}-\mathrm{Cd}$ concentrations $(\mathrm{rs}=0.854, \mathrm{p}=0.000)$. The appearances of syncytial knot (STK) and fibrinoid deposit (Fd) were obviously greater in $\mathrm{H}-\mathrm{Cd}$ group than in $\mathrm{L}-\mathrm{Cd}$ group $(\mathrm{p}=0.007, \mathrm{p}=0.026$ ). The STK was positively correlated with both $\mathrm{Fd}(\mathrm{rs}=0.572, \mathrm{p}=0.032)$ and $\mathrm{P}-\mathrm{Cd}$ concentration $(\mathrm{rs}=0.766, \mathrm{p}=0.001)$. Although the chorioamnitis and decidual inflammation features were found in both groups but the appearance in $\mathrm{H}-\mathrm{Cd}$ group seems to be more severe than in L-Cd group. From these results, we suggested that high $\mathrm{Cd}$ level in placenta may be involved in morphological changes, especially STK and Fd increasing and probably disturb the connection between maternal and fetal circulation.

KEY WORDS: Cadmium; Placenta; Syncytial knot; Fibrinoid materials.

\section{INTRODUCTION}

Cadmium $(\mathrm{Cd})$ is a toxic metal that naturally found in the earth's crust. The usage of phosphate fertilizer in agriculture and usage of $\mathrm{Cd}$ in industry result in the widespread dispersion of this metal into the environment and human foodstuffs (Satarug et al., 2003). In addition, cigarette smoke has been reported as the largest source of Cd exposure in the smoker (Zalups \& Ahmad, 2003). Even though the $\mathrm{Cd}$ uptake was detoxified by the metal binding protein such as metallothionein (MT) but the high level of Cd uptake was able to accumulate in various human organs (Sakulsak, 2012). In human and animal studies, $\mathrm{Cd}$ accumulation induced many adverse effects on various organs such as liver, kidney as well as placenta (Samarawickrama \& Webb, 1979;
Osman et al., 2000; Kuriwaki et al., 2005; Kippler et al., 2010).

Placenta is a developed organ during pregnancy for protection and supporting fetal growth. However, placenta is considered as an indicator organ for heavy metal exposure (Sorkun et al., 2007). Many studies revealed that $\mathrm{Cd}$ accumulation in human placenta involved in morphological changes of placenta and fetal development. For example, alterations of intervillous space, fetal capillaries, villous membrane thickness in placental tissues, and low birth weight neonate were noted in high $\mathrm{Cd}$-contaminated placenta of pregnant smoker (Bush et al., 2000). Additionally, an

\footnotetext{
* Department of Anatomy, Faculty of Medical Science, Naresuan University, Phitsanulok, Thailand.

** Faculty of Medical Science, Naresuan University, Phitsanulok, Thailand.

*** Department of Biochemistry, Faculty of Medical Science, Naresuan University, Phitsanulok, Thailand.

***** Division of Community Public Health, Faculty of Science, BurirumRajabhat University, Burirum, Thailand.

****** Department of Anatomy, Faculty of Medicine, KhonKaen University, KhonKaen, Thailand.

******* Department of Community and Social Medicine, Mae Sot General Hospital, Tak, Thailand.
} 
PHUAPITTAYALERT, L.; NORKAEW, T.; SUPANPAIBOON, W.; CHUENCHOOJIT, S.; HIPKEAO, W.; SWADDIWUDHIPONG, W. \& SAKULSAK, N. Increasing of syncytial knot and fibrinoid deposit in high-Cd accumulated human placentas. Int. J. Morphol., 31(4):1210-1215, 2013.

aggregation of syncytiotrophoblast (STB) cells which is called syncytial knot (STK) is considered as Cd-induced morphological changes (Sorkun et al.; Akbulut et al., 2009) which is resulted from hypoxia (Heazell et al., 2007). Moreover, other histological findings such as fibrinoid deposit (Fd) (Kaufmann et al., 1996; Bane \& Gillian, 2003), and polymorphonuclear (PMN) cell infiltration in chorionic plate (histological chorioamnionitis; HCA) (Murtha et al., 2002; Redline et al., 2003) and in basal plate (decidual inflammation) were considered as histopathologies in placenta as well. Furthermore, Cd has pro-inflammatory properties, which induce chemokine IL- 8 recruiting neutrophil and macrophage (Olszowski et al., 2012). It might be possible that $\mathrm{Cd}$ can induce these morphological changes. Therefore, we aimed to investigate the effects of environmental $\mathrm{Cd}$ exposure on morphological changes in human placenta.

\section{MATERIAL AND METHOD}

Participants and sample collections. This study was conducted under the human ethics committee of Naresuan University, Thailand. Fourteen healthy pregnant women, who resided in Mae Sot sub-district, Tak province and registered at antenatal care units of Mae Sot general hospital between October 2010 and February 2011, were recruited to take part in the study. The pregnant woman who had smoking and alcohol drinking habits was not allowed to be a participant. Then, they were divided into 2 groups according to the placental Cd level; L-Cd group < $15 \mathrm{mg} / \mathrm{kg}$ and $\mathrm{H}-\mathrm{Cd}$ group $\geq 15 \mathrm{mg} / \mathrm{kg}$. Then, maternal blood and urine were collected for $\mathrm{Cd}$ measurement at 36 weeks of gestational age. After delivery, the full term-placentas and cord blood were collected immediately and placental weight was measured. Then, central parts of all placentas were collected according to previous study (Kippler et al.). The samples were kept in metal-free cryotubes at -20C for $\mathrm{Cd}$ analysis and were fixed in $4 \%$ paraformaldehyde in $0.1 \mathrm{M}$ phosphase buffer saline $\mathrm{pH} 7.4$ for histological examination.

The measurements of $\mathrm{Cd}$ concentrations in blood, urine, placenta and cord blood. For placental $\mathrm{Cd}$ concentration (P-Cd) measurement, standard solutions were prepared from Cd-ICP standards (Merck, Germany). One g placental tissues were added with $5 \mathrm{ml}$ nitric acid and were digested at $200^{\circ} \mathrm{C}$ for $20 \mathrm{~min}$. These samples were cooled down at room temperature and adjusted the volume by deionized distilled water to $25 \mathrm{ml}$. Then, the $\mathrm{P}-\mathrm{Cd}$, were measured by inductively coupled plasma mass spectrometer (ICP-MS) (Agilent, Japan).

Fifty $\mu \mathrm{l}$ blood, cord blood and urine were added by
$200 \mu \mathrm{l}$ matrix modifier containing $0.05 \mathrm{mg}$ NH4H2PO4 and $0.003 \mathrm{mg} \mathrm{Mg}(\mathrm{NO} 3) 2$ (Merck, Germany). Deionized distilled water was used as the blank. The blood $\mathrm{Cd}(\mathrm{B}-\mathrm{Cd})$, cord blood $\mathrm{Cd}(\mathrm{C}-\mathrm{Cd})$ and urinary $\mathrm{Cd}(\mathrm{U}-\mathrm{Cd})$ concentrations were analyzed by graphite furnace atomic absorption spectrophotometry (GF-AAS) (Agilent, Japan).

Histological examination. After tissue processing, placental samples were cut into $5 \mu \mathrm{m}$-thickness. The deparaffinized and rehydrated sections were performed through xylene and graded ethanol series. Then, the placental sections were stained with hematoxylin and eosin dyes. Finally, the histological changes in the placenta were observed under light microscope (Eclipse 80i, Nikon) and the photographs were taken for further analysis by Image J software base on NIH.

The data were analyzed by SPSS 15.0 for windows evaluation version software. The independent t-test and Mann-Whitney U- test were used for statistical different determination between 2 groups. In addition, the relations between 2 variables were analyzed by spearman's rank correlation. The data were shown in Mean \pm SEM the statistical significance level was set at $p$-value $\leq 0.05$.

\section{RESULTS}

Maternal and neonatal characteristics. General maternal characteristics were represented in Table I. The mean ages of pregnant women in $\mathrm{H}-\mathrm{Cd}$ and $\mathrm{L}-\mathrm{Cd}$ groups were $25.00 \pm 2.24$ and $25.83 \pm 2.78$ years, respectively $(\mathrm{p}=0.836)$. Additionally, mean body weights, heights and body mass index (BMI) in both groups were not significantly different ( $p>0.05)$. The mean parities, number of children, in $\mathrm{L}-\mathrm{Cd}$ and $\mathrm{H}-\mathrm{Cd}$ groups were $2.00 \pm 0.69$ and $1.71 \pm 0.36$, respectively $(\mathrm{p}=1.000)$. Moreover, mean living times in $\mathrm{L}$ $\mathrm{Cd}$ group was similar to in $\mathrm{H}-\mathrm{Cd}$ group $(\mathrm{p}=0.710)$. Furthermore, the mean placental weights were 512.50 \pm 31.46 and $525 \pm 32.27 \mathrm{~g}$ in L-Cd and $\mathrm{H}-\mathrm{Cd}$ groups, respectively $(\mathrm{p}=0.886)$.

The neonatal characteristics were represented in Table I as well; the mean gestational ages of both groups were approximately 39 weeks. There were no differences in mean birth length, head and chest circumferences of infants in both groups ( $p>0.05)$. The mean birth weight of infants were not statistically different between 2 groups $(3,114.29 \pm 155.35$ and $2,951.42 \pm 85.81, \mathrm{p}=0.530$ ).

The Cd concentrations in blood, urine, placenta and cord blood. As shown in Table II, the B-Cd and U-Cd concentrations in $\mathrm{H}-\mathrm{Cd}$ group was remarkably higher than 
PHUAPITTAYALERT, L.; NORKAEW, T.; SUPANPAIBOON, W.; CHUENCHOOJIT, S.; HIPKEAO, W.; SWADDIWUDHIPONG, W. \& SAKULSAK, N. Increasing of syncytial knot and fibrinoid deposit in high-Cd accumulated human placentas. Int. J. Morphol., 31(4):1210-1215, 2013.

Table I. The characteristics of mother and neonate.

\begin{tabular}{lccc}
\hline Variables & L-Cd group $(\mathbf{n}=7)$ & H-Cd group $(\mathbf{n}=7)$ & $\boldsymbol{p}$-value \\
\hline Maternal characteristics & & & \\
Age (year) & $25.00 \pm 2.25$ & $25.83 \pm 2.78$ & 0.836 \\
Body weight $(\mathrm{kg})$ & $66.57 \pm 4.80$ & $63.42 \pm 4.46$ & 0.945 \\
Height (m) & $1.57 \pm 0.02$ & $1.56 \pm 0.30$ & 0.732 \\
BMI $\left(\mathrm{kg} / \mathrm{m}^{2}\right)$ & $31.64 \pm 2.03$ & $26.03 \pm 1.20$ & 0.836 \\
Parity & $2.00 \pm 0.69$ & $1.71 \pm 0.37$ & 1.000 \\
Living time (years) & $25.00 \pm 2.254$ & $25.71 \pm 3.49$ & 0.620 \\
Placental weight (g) & $512.50 \pm 31.46$ & $525 \pm 32.27$ & 0.886 \\
Infant characteristics & & & \\
Gestational age (week) & $39.43 \pm 0.52$ & $39.40 \pm 0.87$ & 1.000 \\
Birth weight $(\mathrm{g})$ & $3114.29 \pm 155.35$ & $2950.00 \pm 100.00$ & 0.530 \\
Birth length (cm) & $51.71 \pm 0.99$ & $51.60 \pm 0.93$ & 0.876 \\
Head circumference (cm) & $32.36 \pm 0.56$ & $33.40 \pm 0.81$ & 0.343 \\
Chest circumference (cm) & $33.50 \pm 0.93$ & $31.80 \pm 0.49$ & 0.343 \\
\hline
\end{tabular}

Table II. The Cd concentrations in blood, urine, placenta and cord blood.

\begin{tabular}{llll}
\hline Cd concentrations & L-Cd group & H-Cd group & $\boldsymbol{p}$-value \\
\hline Blood Cd $(\mu \mathrm{g} / \mathrm{L})$ & $0.49 \pm 0.05$ & $1.76 \pm 0.37$ & $0.001^{* *}$ \\
Placental Cd $(\mu \mathrm{g} / \mathrm{kg})$ & $9.42 \pm 0.87$ & $34.88 \pm 8.79$ & $0.001^{* *}$ \\
Cord blood Cd $(\mu \mathrm{g} / \mathrm{L})$ & $0.17 \pm 0.05$ & $0.58 \pm 0.22$ & 0.114 \\
Urinary Cd $(\mu \mathrm{g} / \mathrm{g}$ creatinine) & $0.84 \pm 0.05$ & $3.15 \pm 1.10$ & $0.001 * *$ \\
\hline$* * p<01$ & & &
\end{tabular}

in L-Cd group approximately 3.5 and 4 folds $(\mathrm{p}=0.001)$. The increasing of B-Cd concentrations were obviously associated with U-Cd concentration ( $\mathrm{rs}=0.823, \mathrm{p}=0.000)$. As we expected, $\mathrm{P}-\mathrm{Cd}$ concentration of $\mathrm{H}-\mathrm{Cd}$ group was significantly higher than of L-Cd group $(\mathrm{p}=0.001)$. The $\mathrm{P}-$ $\mathrm{Cd}$ levels were positively related with $\mathrm{B}-\mathrm{Cd}$ and $\mathrm{U}-\mathrm{Cd}$ as well ( $r s=0.854, p=0.000$ and $r s=0.743, p=0.002)$. In addition, the $\mathrm{C}-\mathrm{Cd}$ level in $\mathrm{H}-\mathrm{Cd}$ group was much higher than in L$\mathrm{Cd}$ group about 3 folds and directly related with $\mathrm{P}-\mathrm{Cd}$ concentrations ( $r s=0.721, \mathrm{p}=0.044)$.

Morphological changes in Cd-exposed placenta. Histological chorioamnionitis (HCA) is an infiltration of polymorphonuclear (PMN) leukocyte in fetal membrane; either amnion or chorion of placenta (Edwards, 2005). According to the study of Redline and colleagues (Redline et al.), HCA was classified into 3 stages following; stage I is PMN infiltrations in subchorionic plate or few scattered in the lower half of chorionic plate (Fig. 1A). Stage II is diffusepatchy PMN in fibrous chorion and/or amnion (Fig. 1B). And stage III is PMN karyorrheis or amniocyte necrosis. In our study, the stage I HCA was $80 \%$ (4/5) in L-Cd group and $25 \%(1 / 4)$ in H-Cd group. Additionally, stage II HCA in the chorionic plate was found $20 \%$ (1/5) in L-Cd group and $75 \%$ (3/4) in H-Cd group (Fig. 1G). From these findings, they seem to be more HCA severity in placenta of $\mathrm{H}-\mathrm{Cd}$ group than in L-Cd group.

In addition, we have found that the mean number of $\mathrm{STK} /$ villous area in $\mathrm{H}-\mathrm{Cd}$ group was remarkably greater than in L-Cd group approximately 2 folds $(\mathrm{p}=0.007$ ) (Fig. 1C, D and $\mathrm{H})$. Additionally, the increased STK in placenta was positively related with $\mathrm{P}-\mathrm{Cd}$ concentration $(\mathrm{rs}=0.766, \mathrm{p}=$ 0.001). Moreover, fibrinoid deposit (Fd), an acellular and histologically glossy material was regularly found in placenta. However, it has reported that it was one of pathological findings in the placenta. The Fd replaces the blood clotting after STB degeneration (Kaufmann et al.). The mean Fd area/villous area in H-Cd group (Fig. 1D) was significantly enlarger than in L-Cd group $(\mathrm{p}=0.026)$ (Fig. 1C). Interestingly, the $\mathrm{Fd}$ in placenta was positively associated with STK ( $r s=0.572, p=0.032)$. 
According to the classification of HCA (Redline et $a l$.), we have created the stage of decidual inflammation, PMN infiltration into basal plate, based on area of infiltration as followed: Stage I is scattered PMN infiltration in basal plate (Fig. 1E) whereas the PMN infiltration in basal plate and villus along the basal plate is classified as stage II (Fig. 1F). The results were found that the stage $\mathrm{I}$ is not found in $\mathrm{H}-\mathrm{Cd}$ group whereas been shown in L-Cd group about $50 \%$. The stage II is more prominent in $\mathrm{H}$-Cd group $(5 / 5$ or $71.43 \%)$ than in LCd group (2/4 or $50 \%$ ) as shown in Figure $1 \mathrm{G}$.

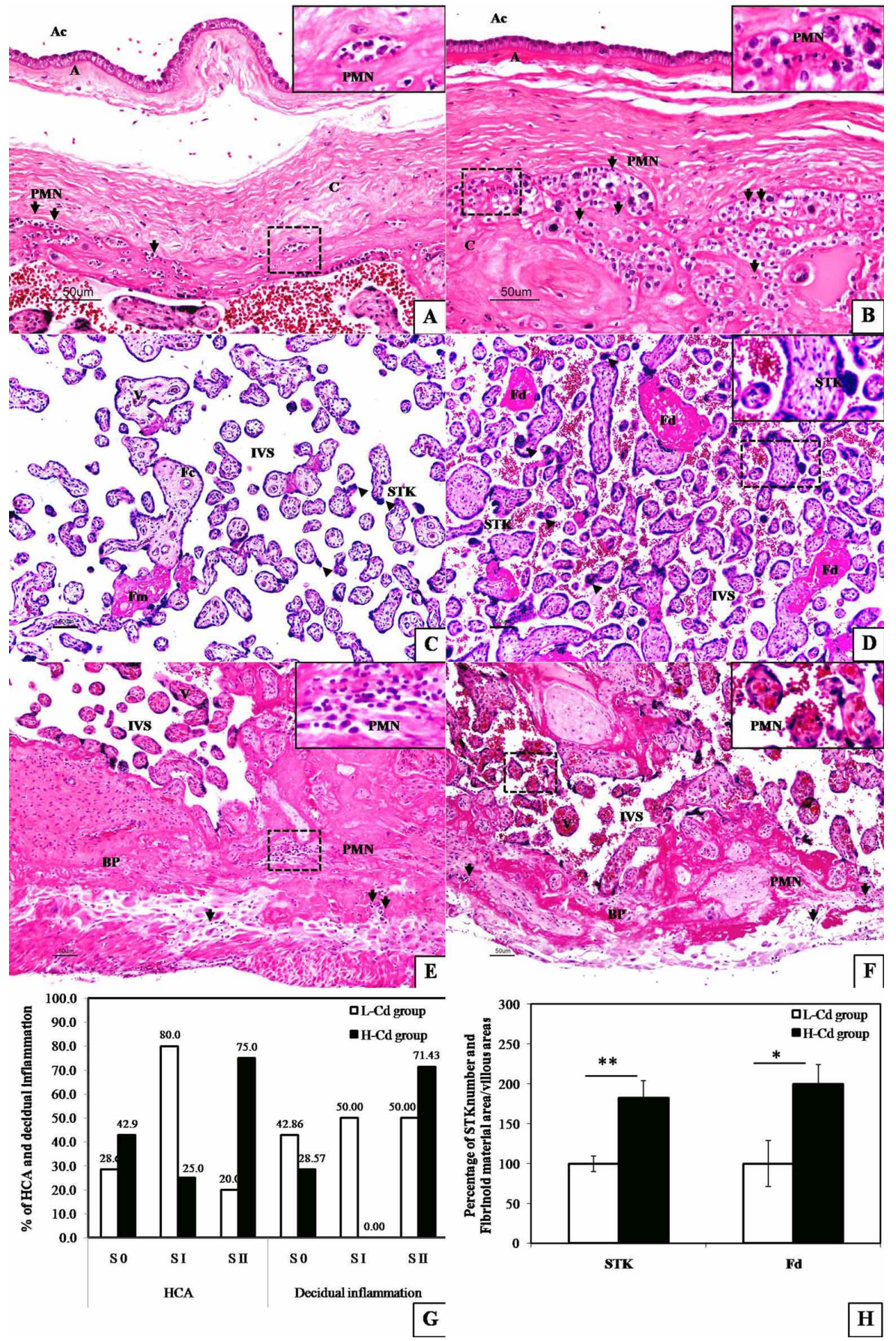

Fig. 1. Morphological change in human placenta (A-F), the quantitative analysis of HCA and decidual inflammation $(\mathrm{G})$ and of STK and Fd (H):Infiltration of PMN cells (arrow) in subchorion or stage I of HCA (Fig A); Infiltration of PMN cells in Chorion or stage II HCA (Fig B). The numbers of syncytial knot (STK) and fibrinoid deposit (Fd) were smaller in $\mathrm{L}-\mathrm{Cd}$ group than in $\mathrm{H}-\mathrm{Cd}$ group (fig $\mathrm{C}$ and D). The stage I decidual inflammation was shown in Fig E whereas the stage II decidual inflammation with villitis along basal plate (BP) as shown in Fig F. The quantitative analysis of HCA and decidual inflammation found that the severity of these morphological features tend to be occurred in $\mathrm{H}-\mathrm{Cd}$ group than in L$\mathrm{Cd}$ group (Fig G). The quantitative analysis showed that the STK and $\mathrm{Fd}$ were greater in $\mathrm{H}-\mathrm{Cd}$ group than in L-Cd group ( $\mathrm{p}=0.007,0.026$; $* \mathrm{p}<0.05, * * \mathrm{P}<0.01)$ as shown in Fig $\mathrm{H}$. $\mathrm{Ae}=$ amnionic epithelium; $\mathrm{Am}=$ amnionic mesoderm; $\mathrm{Sl}=$ spongy layer; $\mathrm{Cm}=$ chorionic mesoderm; $\mathrm{Bm}=$ basement membrane; $\mathrm{Lf}=$ Langerhans' fibrinoid stria; IVS= intervillous space; $\mathrm{V}=$ chorionic villus; $\mathrm{STK}=$ syncytial knot; $\mathrm{Fd}=$ fibrinoid deposit. 
Thai people and is reported to be contaminated with $\mathrm{Cd}$ exceeding the provisional maximal level of $0.2 \mathrm{mg} / \mathrm{kg}$ (Simmons et al., 2005). Therefore, the person who mainly consumed rice grown in the Cd-contaminated area had higher U-Cd than those who did not (Swaddiwudhipong et al., 2007).

After Cd uptake, it is mainly accumulated in target organs, liver and kidney (Kuriwaki et al.). However, other organs including placenta have been reported to retain $\mathrm{Cd}$ which is used as indicator organ for Cd exposure (Bush et al., 2000; Osman et al.; Sorkun et al.). Interestingly, all pregnant women who had high P-Cd level also reside in Mae Ku, Mae Tao and PrathatPhadeang where were reported as high Cd-contaminated areas (Simmons et al.). This finding was in agreement with the studies in Swedish, Turkish and Bangladesh pregnant women who living in air polluted and $\mathrm{Cd}$-contaminated areas (Osman et al.; Sorkun et al.; Kippler et al.).

This Cd accumulation was reported to alter the morphology and function of placenta relating neonatal interference. The morphological appearance of STK in our study was similar to previous study that reported an increased STK in the placenta of pregnant women who resided in air polluted area (Sorkun et al.). An excessive number of STK in placenta resulted in inadequate fetal circulation due to maternal flow obstruction at the group of these nuclei (Jones \& Fox, 1977). Furthermore, this STK was formed after various conditions such as hypoxia, hyperoxia and ROS exposure (Heazell et al.). The features of STK nuclei are classified by pyknosis, peripheral chromatin condense and fusion of cell membrane which is similar to those described in apoptosis (Heazell et al.). Additionally, Cd involves in mitochondria, caspases, and ROS pathways, all seems to play a role in Cdinduced apoptosis (Pulido \& Parrish, 2003). Therefore, we suggested that Cd may be involved in the STK formation in the placenta. Moreover, the increased STK was frequently seen in association with $\mathrm{Fd}$ (Heazell et al.) that was similar to our study. The Fd is derived from blood clotting or degenerative processes of STB (Kaufmann et al.). The study of glycosis blockage caused STB degeneration and immediately followed by blood clot at the trophoblast surface (Kaufmann et al.). The increased accumulation of Fd at denudation site of placenta was also reported in smoker (Mayhew et al., 2003). From our results, we suggested that the increased Fd probably occurred to replace the injury site after STB apoptosis.

About other morphological changes, the feature of HCA and decidual inflammation were PMN infiltration. In general, the most cases of HCA can occur with no any clinical signs. Moreover, twenty percent of HCA can be found in term deliveries whereas upto $50 \%$ can be found in pre-term deliveries (Edwards, 2005). However, all pregnant women in this study were full-term delivery. Although HCA were not much different between 2 groups, it seems to be more severity of HCA and decidual inflammation in $\mathrm{H}-\mathrm{Cd}$ group than in $\mathrm{L}-\mathrm{Cd}$ group. Previous study was reported that $\mathrm{Cd}$ has pro-inflammatory property by activates IL- 8 resulting in recruiting neutrophil and macrophages after $\mathrm{Cd}$ exposure (Olszowski et al.). Hence, $\mathrm{Cd}$ may involve in PMN infiltration in the placenta.

In this study, we suggest that $\mathrm{Cd}$ is likely entering the human body by food chain. Then, it can be accumulated in many organs including placenta and probably induced morphological changes in placenta, especially STK and Fd formations. These STK and Fd appearances may further disturbed the fetomaternal circulation. Then, the apoptosis in Cd-accumulated placenta should be further investigated.

\section{ACKNOWLEDGEMENTS}

We are grateful for Commission on Higher Education (CHE) funding under Strategic Scholarships for Frontier Research Network for the Joint Ph.D. Program. And we would like to express our sincere thanks to all staffs of Mae Sot General Hospital and toxic metal research group (TMRG), Naresuan University for collaboration and samples collection.

PHUAPITTAYALERT, L.; NORKAEW, T.; SUPANPAIBOON, W.; CHUENCHOOJIT, S.; HIPKEAO, W.; SWADDIWUDHIPONG, W. \& SAKULSAK, N. Aumento del nodo sincicial y depósitos de fibrinoide en placentas humanas con alta acumulación de Cadmio. Int. J. Morphol., 31(4):1210-1215, 2013.

RESUMEN: Un metal tóxico, el cadmio (Cd), se puede acumular en órganos humanos. La placenta se utiliza, por lo general, como órgano indicador de la exposición a Cd. Nuestro objetivo fue investigar la diferente morfología placentaria entre las placentas con baja y alta acumulación de Cd. Las muestras fueron recolectadas de 14 mujeres embarazadas que residían áreas con alta (grupo H-Cd) y baja contaminación por Cd (grupo L$\mathrm{Cd}$ ). Las concentraciones de Cd en la sangre (B- Cd), orina (U-Cd) y placentas (P-Cd) se midieron por ICP-MS y AAS. La apariencia morfológica de las placentas fue examinada usando cortes histológicos teñidos con H-E. Los resultados mostraron que los niveles de B-Cd, U-Cd y P-Cd fueron significativamente mayores en el grupo $\mathrm{H}-\mathrm{Cd}(\mathrm{p}=0,001)$. Por otra parte, el B-Cd se correlacionó positivamente con las concentraciones de $\mathrm{U}-\mathrm{Cd}(\mathrm{rs}=$ $0,854, \mathrm{p}=0,000)$ y P-Cd ( $\mathrm{rs}=0,823, \mathrm{p}=0,000)$. Las apariciones de nodos sinciciales (NS) y depósitos fibrinoides (Fd) fueron mayores en el grupo H-Cd ( $r s=0,007, p=0,026)$. Los ND se correlacionaron positivamente con los $\mathrm{Fd}(\mathrm{rs}=0,572, \mathrm{p}=0,032)$ y la concentración de $\mathrm{P}-\mathrm{Cd}(\mathrm{rs}=0,766, \mathrm{p}=$ 0,001). Aunque características de corioamnitis e inflamación de la decidua se encontraron en ambos grupos, su aparición en el grupo H-Cd pareció ser más grave que en el grupo L-Cd. A partir de estos resultados, sugerimos que el nivel alto de $\mathrm{Cd}$ en la placenta puede estar involucrado en los cambios morfológicos, especialmente el aumento de NS y Fd, los que probablemente alteran la relación entre la circulación materna y fetal.

PALABRAS CLAVE: Cadmio; Placenta; Nodo sincicial; Materiales fibrinoides. 


\section{REFERENCES}

Akbulut, M.; Sorkun, H. C.; Bir, F.; Eralp, A.\& Duzcan, E. Chorangiosis: The potential role of smoking and air pollution. Pathol. Res. Pract., 205(2):75-81, 2009.

Bane, A. \& Gillian, J. E. Massive perivillous fibrinoid causing recurrent placental failure. BJOG, 110(3):292-5, 2003

Bush, P. G.; Mayhew, T. M.; Abramovich, D. R.; Aggett, P. J.; Burke, M. D.\& Page, K. R. A Quantitative Study on the Effects of Maternal Smoking on Placental Morphology and Cadmium Concentration. Placenta, 21(2-3):247-56, 2000.

Edwards, R. K. Chorioamnionitis and Labor. Obstet. Gynecol. Clin. North Am., 32(2):287-96, 2005.

Heazell, A. E.; Moll, S. J.; Jones, C. J..; Baker, P. N. \& Crocker, I. P. Formation of syncytial knots is increased by hyperoxia, hypoxia and reactive oxygen species. Placenta, 28(Suppl. A):S33-40, 2007.

Jones, C. J. \& Fox, H. Syncytial knots and intervillous bridges in the human placenta: an ultrastructural study. J. Anat., 124(Pt. 2):275-86, 1977.

Kaufmann, P.; Huppertz, B. \& Frank, H. G. The fibrinoids of the human placenta: origin, composition and functional relevance. Ann. Anat., 178(6):485-501, 1996.

Kippler, M.; Hoque, A. M.; Raqib, R.; Ohrvik, H.; Ekstrom, E. C.\& Vahter, M. Accumulation of cadmium in human placenta interacts with the transport of micronutrients to the fetus. Toxicol. Lett., 192(2):162-8, 2010.

Kuriwaki, J.; Nishijo, M.; Honda, R.; Tawara, K.; Nakagawa, H.; Hori, E. \& Nishijo, H. Effects of cadmium exposure during pregnancy on trace elements in fetal rat liver and kidney. Toxicol. Lett., 156(3):369-76, 2005.

Mayhew, T. M.; Brotherton, L.; Holliday, E.; Orme, G. \& Bush, P. G. Fibrin-type Fibrinoid in Placentae from Pregnancies Associated with Maternal Smoking: Association with Villous Trophoblast and Impact on Intervillous Porosity. Placenta, 24(5):501-9, 2003.

Murtha, A. P.; Auten, R. \& Herbert, W. N. Apoptosis in the chorion laeve of term patients with histologic chorioamnionitis. Infect. Dis. Obstet. Gynecol., 10(2):93-6, 2002.

Olszowski, T.; Baranowska-Bosiacka, I.; Gutowska, I. \& Chlubek, D. Pro-inflammatory properties of cadmium. Acta Biochim. Pol.,59(4):475-82, 2012.

Osman, K.; Akesson, A.; Berglund, M.; Bremme, K.; Schutz, A.; Ask, K. \& Vahter, M. Toxic and essential elements in placentas of Swedish women. Clin. Biochem., 33(2):131-8, 2000.
Pulido, M. D. \& Parrish, A. R. Metal-induced apoptosis: mechanisms. Mutat. Res., 533(1-2):227-41, 2003.

Redline, R. W.; Faye-Petersen, O.; Heller, D.; Qureshi, F.; Savell, V.; Vogler, C. \& Society for Pediatric Pathology, Perinatal Section, Amniotic Fluid Infection Nosology Committee. Amniotic Infection Syndrome: Nosology and Reproducibility of Placental Reaction Patterns. Pediatr. Dev. Pathol., 6(5):435$48,2003$.

Sakulsak, N. Metallothionein: An overview on its metal homeostasis regulation in mamals. Int. J. Morphol., 30(3):1007-12, 2012.

Samarawickrama, G. P. \& Webb, M. Acute effects of cadmium on the pregnant rat and embryo-fetal development. Environ. Health Perspect., 28:245-9, 1979.

Satarug, S.; Baker, J. R.; Urbenjapol, S.; Haswell-Elkins, M.; Reilly, P. E.; Williams, D. J. \& Moore, M. R. A global perspective on cadmium pollution and toxicity in non-occupationally exposed population. Toxicol. Lett., 137(1-2):65-83, 2003.

Simmons, R. W.; Pongsakul, P.; Saiyasitpanich, D. \& Klinphoklap, S. Elevated Levels of Cadmium and Zinc in Paddy Soils and Elevated Levels of Cadmium in Rice Grain Downstream of a Zinc Mineralized Area in Thailand: Implications for Public Health. Environ. Geochem. Health, 27(5-6):501-11, 2005.

Sorkun, H. C.; Bir, F.; Akbulut, M.; Divrikli, U.; Erken, G.; Demirhan, H.; Duzcan, E.; Elci, L.; Celik, I. \& Yozgatli, U. The effects of air pollution and smoking on placental cadmium, zinc concentration and metallothionein expression. Toxicology, 238(1):15-22, 2007.

Swaddiwudhipong, W.; Limpatanachote, P.; Mahasakpan, P.; Krintratun, S. \& Padungtod, C. Cadmium-exposed population in Mae Sot District, Tak Province: 1 . Prevalence of high urinary cadmium levels in the adults. J. Med. Assoc. Thai., 90(1):1438, 2007.

Zalups, R. K. \& Ahmad, S. Molecular handling of cadmium in transporting epithelia. Toxicol. Appl. Pharmacol., 186(3):163$88,2003$.

Correspondence to:

Natthiya Sakulsak, PhD

Department of Anatomy

Faculty of Medical Science

Naresuan University

Phitsanulok, 65000

THAILAND

Email: nsakulsak@yahoo.com
Received: 09-07-2013

Accepted: 28-08-2013 